\title{
Later careers - regenerating the medical workforce
}

\author{
Author: Harriet Gordon
}

We have a medical workforce crisis where we have insufficient trainees, demonstrated by rota gaps, and in turn nearly half of advertised consultant physician posts cannot be appointed to. Most physicians retire around age 62 , and already $5 \%$ of the total consultant workforce is those who have retired and returned. If those reaching retirement age chose not to retire but continue working less than full time this would, at least in part, benefit the workforce and utilise valuable skills and experience to the benefit of the individual, the wider medical community and therefore our patients.

KEYWORDS: Medical workforce, flexible working, retirement

\section{Background}

We are currently in the midst of a workforce crisis where the number of consultants has not risen to meet the workload, exacerbated already this year with physicians required to divert activity away from elective care to manage emergencies.

In the last Royal College of Physicians (RCP) census $45 \%$ of the 1,485 consultant posts advertised were not appointed to, ${ }^{1}$ due to a lack of trainees and there are similar problems across the medical profession to a greater or lesser extent. The lack of trainees is manifested by rota gaps: $53 \%$ consultant physicians reported trainee rota gaps frequently or often, in $20 \%$ causing concerns for patient safety. ${ }^{1}$ The consultant physician appointment rate has fallen since 2008 (73\%) to 55\% in 2017 (Fig 1). ${ }^{2}$

New medical student places are coming on line, but it will take at least 17 years for these students to reach substantive posts. Now and in the interim we are dependent on overseas help: $23 \%$ of all UK consultant graduated overseas; the greatest contribution ( $47 \%$ of these) from the Indian subcontinent. ${ }^{1}$ Brexit seems likely to deter European trainees and there have already been fewer Europeans applying to medical schools. Potentially, however, if Home Office regulations allow, non-EU doctors such as Australasians may be facilitated in working in the UK. Help has also come from other professions, nurses, pharmacists and most recently from physician associates.

\section{Current working after retirement}

The average retirement age is 62 years, and there will probably be about 300 retirements next year, with around 850 certificates

Author: consultant gastroenterologist, The Royal Hampshire County Hospital, and RCP Flexibility and Wellbeing Group

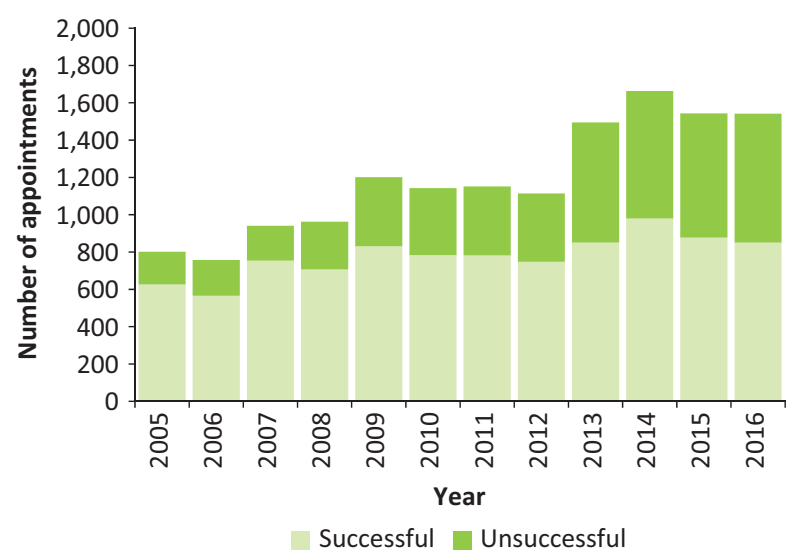

Fig 1. Success of advertised consultant physician appointments.

of completion of training (CCTs) expected; however, given the significant number of consultant posts already unfilled, and rising interests in working less than full time or abroad, this will not result in as many new expansion posts as perhaps 10 years ago. Five percent of the total consultant physician workforce are those who have retired and returned, $81 \%$ working less than full time. ${ }^{1}$ Reasons for working in this age group were cited as greater fulfilment, wanting to work but not as previously, and a desire not to 'throw it all away'. Sixty-nine percent of those aged 55-60 stated that they would ideally like to retire and return rather than retire. ${ }^{3}$ In terms of job satisfaction and wellbeing, consultant physicians in the RCP 2017 wellbeing survey reported feeling less pressurised with increasing age, more fulfilled and confident and increasingly valued by the hospital. ${ }^{3}$ As a 73 -year-old anaesthetist said working post retirement: 'I do not need the money but I need the contact with patients and colleagues which makes me feel useful to the community'.

\section{Initiatives with flexible working}

The number of consultants reaching age 60 over the next decade is set to rise and if those reaching retirement age chose not to retire but to continue to work in some capacity, this could be of great benefit to the workforce. The RCP endorses flexible working and has recommended: 'make flexible or part-time working options available to older physicians where possible.' ${ }^{4}$ With this in mind, Later careers is an RCP initiative to promote and enable working around the current retirement age, in a less-than-full-time capacity, 
to the benefit of the individual, the wider medical community and to our patients. ${ }^{5}$

Prevalent rota gaps have diverted consultant time to acute services from teaching, management and research, all of which erodes much that is of the value in the consultant role. ${ }^{6} \mathrm{~A}$ senior colleague within the department may well be able to enact these valuable roles, or provide backfill to enable others. A recently retired gastroenterologist commented

...there was no automatic approach from the teachers towards me, or knowingly towards my co-retirees, to utilise this experienced and now very available resource. I regarded this as a dismissive waste of medical experience.

Senior consultants may be particularly valuable as mentors. At a time when morale in the medical profession has been low, particularly of junior doctors, the provision of a senior colleague as an exemplar and an ambassador for the specialty is particularly welcome. Bidirectional mentoring should be of benefit to both parties and the wider team.

The major deterrents to continued working have been cited as revalidation and appraisal, departmental scepticism with accusations of 'cherry-picking' careers, and personal concerns regarding competency and health. Concerns regarding revalidation have centred on the workload and requirements of the process. Sir Keith Pearson, independent chair of the revalidation advisory board published on revalidation in $2016 .{ }^{7}$ Key recommendations were to look at practical ways to reduce the time and effort needed to prepare for appraisal; the General Medical Council (GMC) to update on what is mandatory, and where flexibility exists; and that healthcare organisations should provide support in IT systems or investment in administrative support teams. The GMC have published guidance in response to this report. ${ }^{8}$ They have highlighted the need to reduce bureaucracy for doctors and improve IT support. In March this year they plan to publish requirements so that what is needed for revalidation is clearly distinct from requirements set by employers for appraisal. The RCP has further details relevant to later careers, available at www.rcplondon.ac.uk/mythbusters.

Less-than-full-time (LTFT) working should enable continued but less intense working; however, this may be perceived as 'cherrypicking'. At the time of retirement it is likely that the individual is at a professional best in those subspecialties developed over at least a 20-year career and it is natural to want to continue those areas of interest. This should be in the best interests of the unit overall. Discussion within the unit should enable plans to be made to the benefit of the department as a whole, and should take place well before a planned change in working practice. It is recommended that there should be a discussion at the age of 55 on likely plans for the next 5 to 10 years to enable appropriate succession planning. From this appropriate recruitment can begin to be planned and career progression enabled by a senior consultant mentoring and developing a more junior colleague, using the strengths of both. ${ }^{9}$ Job planning as a department enables recognition of individual contribution and effective role distribution.

The Academy of Medical Royal Colleges later careers survey, which involved doctors in all specialties, identified on-call commitments as the main influence to retirement, after pension arrangements. ${ }^{10}$ In the RCP wellbeing survey 2017 on-call came second to personal life as the driver for retirement planning. ${ }^{3}$

\section{What would most improve your career satisfaction?}

More flexible working (sabbatical)

Work more PAs / paid more pro rata

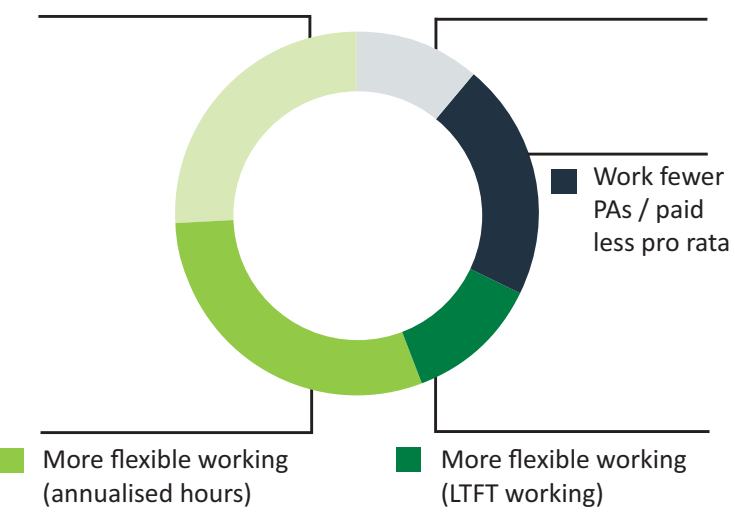

Fig 2. What would most improve your career satisfaction? RCP wellbeing survey $2017^{3}$

Participation in on-call drops through a career, from $44 \%$ at the start to $18 \%$ at the end, and specialty out-of-hours work drops from $80 \%$ at the start of a consultant career to $57 \%$ at the end. ${ }^{1}$ The enthusiasm to sustain a full job plan and stamina for out-of-hours work may reasonably have deteriorated during a consultant career and prompts retirement plans. The Academy of Medical Royal Colleges has recommended that at the age of $60 \mathrm{a}$ consultant should opt into on-call only if they wish to. ${ }^{10}$

As consultants progress through their careers there is a gradual reduction in general medicine (GIM) participation: while over half of all consultants take part in GIM under the age of 40 , this is $25 \%$ aged 60 and over; and $34 \%$ participate in the acute unselected take under 40 years, and $18 \%$ between $60-65$ years. ${ }^{1}$ Although those working less than full time do less GIM and acute take, $11 \%$ of less-than-full-time workers over the age of 60 are still contributing to acute unselected medical take. ${ }^{1}$ There is an increasing need for GIM skills and ambulatory care may enable continued active participation.

\section{Conclusion}

In the 2017 RCP wellbeing survey the most popular option to improve career satisfaction was for annualised hours, followed by opportunities for a sabbatical, suggesting a strong interest in working in less conventional ways (Fig 2). ${ }^{3}$ This could be of benefit within a department if there is demand for annual leave at specific times of year, such as school holidays, such that the consultant working less than full time might agree to work predominantly in the school holidays. Alternatively, it may be preferred to work blocks of time, such as a month on and a month off, thereby enabling other plans to run concurrently.

At a time of poor morale ${ }^{2}$ LTFT working in a later career is of benefit to the individual, the trust and to the wider medical community. To enable this effectively, the role must have credibility with good leadership and communication to avoid fragmentation within the team. There is currently a medical workforce shortage 
and the pension rules are prompting retirement plans sooner for many. New models of later career working are for doctors, hospital staff and policy makers to enable doctors to remain engaged and working around retirement age, working for mutual benefit. In the words of RCP vice president David Oliver,

...if we could change job plans and working environments to support older doctors, better use the skills and experience they do bring and phase in retirement rather than have them fall off a sharp work / retirement cliff edge, surely we should. ${ }^{11}$.

\section{References}

1 Federation of the Royal Colleges of Physicians. Focus on physicians: census of consultant physicians and higher specialty trainees 2017-18. London: RCP, 2018.

2 Royal College of Physicians. Underfunded, underdoctored, overstretched: the NHS in 2016. London: RCP, 2016.

3 Gordon H, Boylan J. Physicians and wellbeing: the latest survey of consultants. RCP Commentary. London: RCP, 2017:10

4 Royal College of Physicians. Keeping medicine brilliant: improving working conditions in the acute setting. London: RCP, 2016.
5 Royal College of Physicians. Later Careers: stemming the drain of expertise and skills from the profession. London: RCP, 2018.

6 Gordon H. The consultant census: rota gaps in 2017. RCP Commentary. London: RCP, April 2017:6

7 General Medical Council. Taking revalidation forward, improving the process of relicensing for doctors. Sir Keith Pearson's review of medical revalidation. GMC, 2017.

8 General Medical Council.Monitoring and evaluating revalidation. www.gmcuk.org/doctors/revalidation/9610.asp [Accessed 29 November 2017].

9 Juhani Ilmarinen. Promoting active ageing in the workplace. European Agency for Safety and Health at Work, 2012.

10 The Academy of Medical Royal Colleges. The Academy of Medical Royal Colleges Later Careers Survey Results. AOMRC, 2017.

11 Oliver D. Keeping older doctors in the job. BMJ 2016;355:i6260.

Address for correspondence: Dr Harriet Gordon, The Royal Hampshire County Hospital, Romsey Road, Winchester SO22 5DG, UK.

Email: Harriet.Gordon@hhft.nhs.uk

\section{Assessing trainees in the workplace An e-learning module for secondary care doctors}

Three hours of CPD-approved interactive learning covering:

$>$ feedback

> supervised learning events (SLEs)

$>$ workplace-based assessments (WPBAs)

$>$ the role of the Annual Review of Competence Progression (ARCP).

For more information please visit: www.rcplondon.ac.uk/elearning

\section{Royal College} of Physicians

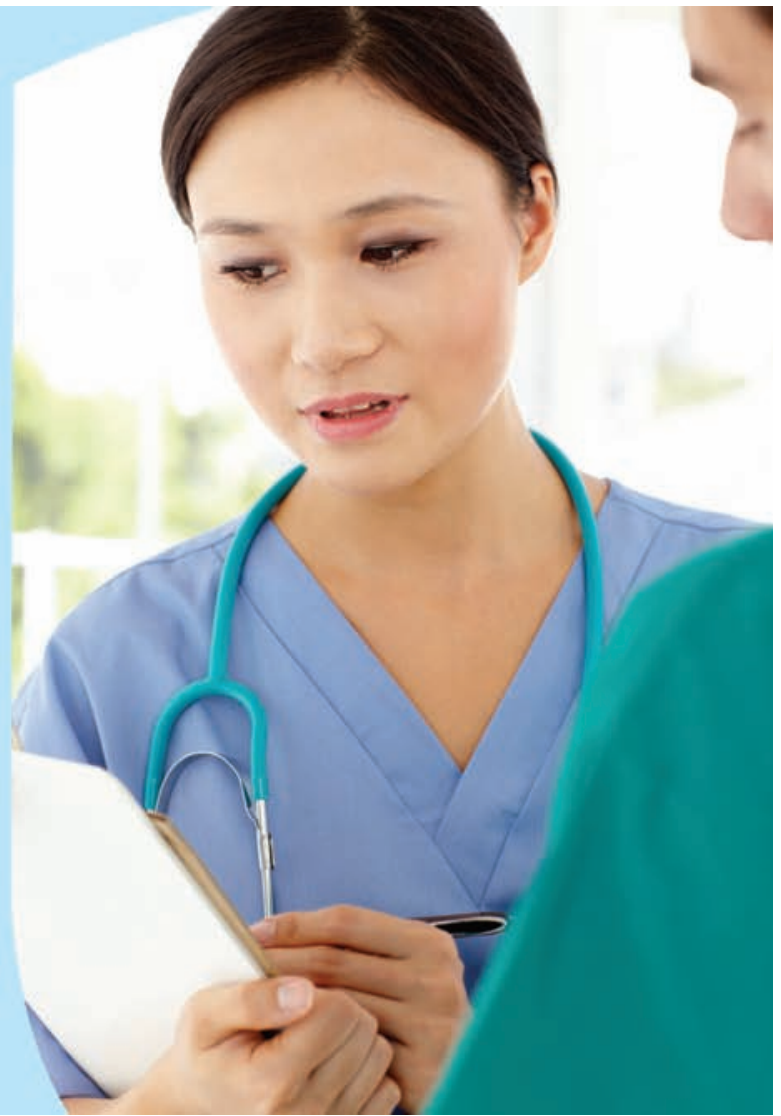

